\title{
Clinical Usefulness of Chest X-Ray in the Detection of Pulmonary Metastases After Curative Resection for Colorectal Cancer: Reply
}

\author{
Won-Suk Lee $\cdot$ Seong Hyeon Yun $\cdot$ Ho-Kyung Chun \\ Woo Yong Lee $\cdot$ Haeran Yun
}

Published online: 7 April 2009

(C) Société Internationale de Chirurgie 2009

We agree with Professor Chartrand-Lefebvre's [1] thoughtful commentary on including chest computed tomography (CT) in the preoperative evaluation of patients for colorectal liver metastases resection and its advantage over performing unnecessary surgery. We now have a wider indication for chest $\mathrm{CT}$ where we include every patient for colorectal cancer preoperatively. It is important to note that in our retrospective study, the right lower lobe or the left lower lobe of the lung was involved in $82.9 \%$ of all pulmonary metastases and that abdominal CT initially showed normal chest scans in 66 of those patients (34.2\%) [2]. In view of this observation, we suggested that elevating the upper level of the scan limit of routine abdominal CT or adding chest CT might result in better detection of pulmonary metastases in a surveillance program.

\section{References}

1. Chartrand-Lefebvre C, Lapointe R, Samson L et al (2008) Chest computed tomography screening in colorectal cancer patients. World J Surg. doi:10.1007/s00268-008-9891-3

2. Lee W-S, Yun SH, Chun H-K et al (2007) Clinical usefulness of chest radiography in detection of pulmonary metastases after curative resection for colorectal cancer. World J Surg 31:15021506

W.-S. Lee $(\bowtie)$

Department of Surgery, Gil Medical Center, Gachon University

of Medicine and Science, 1198 Guwol-dong, Namdong-gu,

Incheon 405-760, Korea

e-mail: 1ws@gilhospital.com

S. H. Yun - H.-K. Chun · W. Y. Lee $\cdot$ H. Yun

Department of Surgery, Samsung Medical Center, Incheon

405-760, Korea 